\title{
Assess the Factors Affecting the Non - Compliance on DOTS regimen among Patients with Tuberculosis in DOTS Centres at Puducherry
}

*MrsRajalakshmi R, **Prof DrKamalam S \& ***Mrs.Suguna Mary D

\begin{abstract}
Tuberculosis still has increased prevalence rate in India and Puducherry though there are pharmacological interventions available to treat Tuberculosis. ${ }^{2}$ It is considered as serious social health problem as it is completely curable because it spreads easily if the preventive measures are not taken. Through this research study the factors were assessed by which measures to improve the quality of life and decrease the incidence and prevalence of TB can beachieved. ${ }^{3}$

A descriptive retrospective cohort research design was undertaken in various areas (Mudaliarpet, Muthialpet, Lawspet, Reddiarpalayam, etc.) of Puducherry. The data was collected from 100 subjects (defaulters) through purposive sampling technique to assess the factors affecting the non - compliance through structured questionnaires. Overall research findings showed that majority 93\% were males, $34 \%$ were alcoholics and $27 \%$ were alcoholics with smoking. There was a significant association between the factors affecting non-compliance under DOTS regimen with selected demographic variables.
\end{abstract}

Key Words: Tuberculosis, Prevalence, Defaulters, Factors, Non-compliance

\section{Introduction}

Though the Union Territory of Puducherry isprovidedwith27PrimaryHealthcentres,

2 Community Health Centres and 1 TB Chest Clinic to issue TB drugs and also the health professionals are insisting the importance of taking the TB drugs regularly, the incidence, prevalence, mortality and morbidity are still very high due to less participation and cooperation from the patient side. ${ }^{1}$ Inorder to know the factors affecting the non - compliance of TB patients researcher has conducted thisstudy.

\section{Objectives}

To identify the prevalence rate of TB patients anddefaulters.

To find out the causative factors amongdefaulters under TBprogramme.
To determine the association between causative factors among defaulters with selected demographicvariables.

\section{Methodology}

Research design - Descriptive retrospective cohortdesign.

Setting - Various areas of Puducherry.

Population - DOTS Regimen Defaulters.

Sample size - 100 .

Sampling technique - Purposive sampling technique.

\section{Major findings}

$>\quad$ The prevalence of TB (JAN 2010 DEC 2012) among Males and females were $35.4 \%$ \& $14.4 \%$ respectively. Almost half of the Children (50.2\%) aged less than 15 years were infected with TB. Amongthem 
$31 \%$ of patients were defaulters \& $0.58 \%$

were diagnosed with HIV.

\section{The causative factors among defaulters} under TB programme

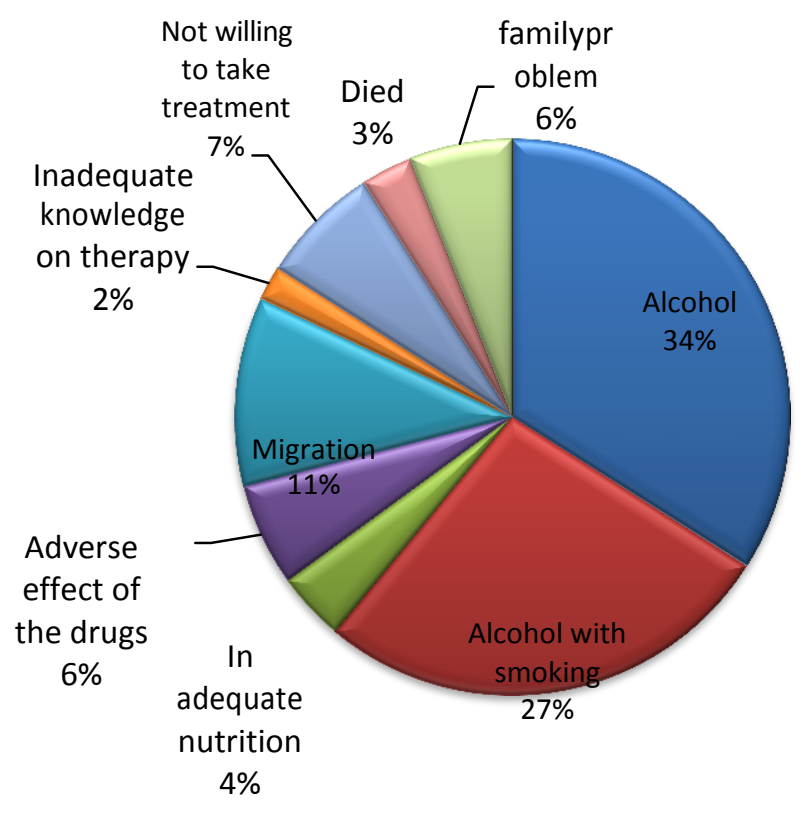

The study predicted the highlysignificant relationship between the middle aged group (40 - 59 years) and factors influencing the non-compliance. $(\mathrm{p}<0.01)$.

The study findings revealed that majority of them were from rural \& there was a significant association between alcoholic consumption and defaulters. $(\mathrm{p}<0.05)$.

There was a significant relationship between defaulters and the factors. $(\mathrm{p}<0.05)$.

\section{Conclusion}

The study findings revealed that the factors associated with defaulters are Alcohol consumption, family problem, inadequate nutrition, adverse effect of the drug, migration, etc;. Tuberculosis is thecurable and also a silent killer as it spreads from one person to other through air and droplet infections. The study concluded that the clients are not adherent to the treatment course. The programme cannot be a

successful one unless there is a "Community Participation”.

\section{References}

1.Weis,S.E.,Slocum,P.C.,Blais, F.X., et al; "The effect of directly observed therapy on the rates of resistance and relapse in Tuberculosis"; N Engl J Med; 1994,330,1179.

2.Allender, "Community Health Nursing: Promoting and protecting the Publics Health", Lippincott, $6^{\text {th }}$ ed.

3.Journal of Infectious Diseases and Immunity, 2011, 3(5),90-95.

4. Sinha.K, "Finally,Tuberculosis declared a notifiable Disease", The times of India, May 9,2012. 